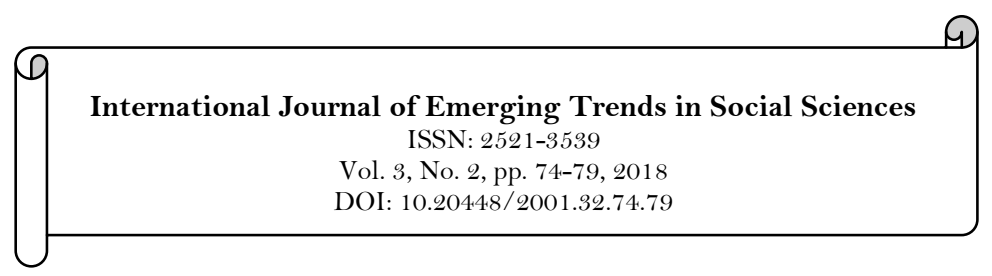

\title{
The Impact of Strategic Drift and Tactical Wear - Out: An Anecdote Example: The Case of the Distribution of Petroleum Products by Nigeria National Petroleum Corporation (NNPC)
}

\author{
Monica Gajere ${ }^{1}$
}

${ }^{1}$ University of Jos, Faculty of Management Sciences, Department of Business Administration, Nigeria.

Email:monicgajere@gmail.com

\begin{tabular}{|c|c|}
\hline Abstract & \\
\hline $\begin{array}{l}\text { The focus of this paper is to give an anecdote example of the impact } \\
\text { of strategic drift and tactical wear - out using the case of the } \\
\text { distribution of petroleum products by Nigeria National Petroleum } \\
\text { Corporation (NNPC). Based on industry internal documentation, } \\
\text { market reports, and the experience of the populace, the reasons for } \\
\text { NNPCS strategic drift and tactical wear - out are based on its } \\
\text { current and historical strategies and tactics. The current practices } \\
\text { have become obsolete because customer needs, human resource } \\
\text { needs, technology, and the environment (political, social and } \\
\text { economic factors) change the rules of the game and these had } \\
\text { impacts on NNPC's business activities. As a result, strategies and } \\
\text { tactics have become tired or worn-out. The paper suggests that } \\
\text { NNPC re-addressed its current strategies in line with the current } \\
\text { environmental factors to avoid drift situations by exploring new } \\
\text { opportunities and exploiting existing ones to avoid strategic drifts. } \\
\text { Also the paper suggests that NNPC could chose between adaptation } \\
\text { and evolution or reconstruction and revolution as a change in the } \\
\text { marketing strategy depending on the degree of the strategic drift or } \\
\text { wear out. }\end{array}$ & $\begin{array}{l}\text { Keywords: } \\
\text { Strategic drift and strategic } \\
\text { wear-out } \\
\text { Nigeria national petroleum } \\
\text { corporation (NNPC) } \\
\text { Distribution. } \\
\text { Licensed: } \\
\text { This work is licensed under a } \\
\text { Creative Commons Attribution } \\
\text { 4.0 License. } \\
\text { Publisher: } \\
\text { Scientific Publishing Institute }\end{array}$ \\
\hline
\end{tabular}

\section{Introduction}

Strategic drift and tactical wear- out is the tight spot that any organisation will find itself if it hold on to its current strategies and tactics without any reassessment to keep abreast of current trends in a competitive and democratic environment. The problem is that current practices become obsolete because customer needs, human resource needs, technology, the environment (political, social and economic factors) and competitors change the rules of the game and these impacts on business activities. When this happens, strategies and tactics become tired or worn-out if not re-addressed.

It is a fact that in Nigeria, security of lives, property, corruption, multiple taxation, political unrest, power supply and labour strikes still constitutes very serious drawbacks to business activities. These must be continuously addressed by organisations in their strategic posturing; otherwise they will be unable to compete favourably in a democratic set up.

Many companies in Nigeria such as the textile, Telecom industries, manufacturing industry, power sector, oil or petroleum industries etc. that were considered in the $80 \mathrm{~s}$ and $90 \mathrm{~s}$ as excellent companies have lost their savour of excellence. Some have either completely vanished from existence or are managing to survive as a result of tactical and strategic drift or wear-out. When this happens, there will be volatility in the organisations which suggests that factors in the environment may force changing patterns of production, consumption and prices which may force the organisation to adjust to the new perceived conditions unprepared.

The exploration, refining, marketing and distribution of petroleum products in Nigeria are important factors in the economy of Nigeria but, since oil was discovered in Nigeria in the 1950s, the country has suffered series of product lack despite the availability of the resource and considerable investments in infrastructure - refineries, storage depots, pipelines, and even payments of bridging cost to both major and 
independent marketers as intermediaries and the establishment of mega petrol stations to ensure effective and efficient distribution. In 2011, the house of representatives reported that the government of Nigeria spent $\mathrm{N}$ 2, 587.087 Trillion as at 31 December 2011, amounting to more than $900 \%$ over the appropriated sum of $\mathrm{N} 245$ billion just to ensure the availability of petroleum products to Nigerians (House of Representative Report, 2012). Unfortunately, the distribution of these petroleum products to storage depots and to consumers has been problematic. With the provision of 445,000 barrels per day (bpd) allocation to NNPC, it is expected that with the refining capacity of $53 \%$ and the SWAP/Offshore processing arrangement of the balance of $47 \%$, should have been sufficient to provide the nation with the needed petroleum products.

The petroleum industry is losing the position it occupies in the economy of Nigeria as a result of consistent fuel scarcity and inefficient petroleum products distribution. This threatens the social, economic and political lives of the people. As a result, Nigeria has witnessed low productivity, reduced investment activities, and most businesses strive on generators because of lack of adequate petroleum products to enable electricity generation to power them.

In the overall, the prevailing fuel crises has affected the total cost of production of goods and services, the cost of doing business (the cost of generating power to do business), the purchasing power of the Nigeria people, their national income and the aggregate growth and performance of the economy as a whole is dwindling. As a result of shortages of petroleum products supply, industries like Dunlop, Marceline, just to mention a few, moved to Ghana. These migrations have created more unemployment, and reduced the volume of investment activities in the country. Also the inefficient petroleum products distribution, enhances the wind of scarcity and product shortages even when products are dispatched for onward distribution to various destinations for local consumption in the country; even at the point of importation for onward distribution, there are challenges that accompany the movement of petroleum products.

The strategic objective of PPMC is to ensure the security and the availability of petroleum products in the country and to be a dependable supplier in the international market (NNPC, 2006). This it does by ensuring that products are distributed or transported from various refineries to different depots, and finally to retail outlets where it can finally reach the consumers. But most times these products do not reach the consumers, even when they do, it does not reach the consumer at the right time and at a reasonable cost.

As the Management guru Peter Drucker once wrote: "Every organization has to prepare for the abandonment of everything it does." therefore most organizations today have to learn to operate in more dynamic, fast-paced environments than they did a few decades ago. These environmental pressures represent the driving forces that push organisations out of their comfort zones.

Most of Nigeria's organisations strategic antennas show no sense of urgency, when current strategies are wearing out. Worse, they still rely on contrived old strategies and tactics rather than the external driving forces to support the change effort. This paper is out to relate the impact of strategic drift and strategic wear out on organisations using the distribution arm of NNPC as a case example.

\subsection{Statement of the problem}

Nigeria national petroleum industry is one of the major distributors of petroleum products in Nigeria. However, in contrast to the situation in other countries where the governments of such countries like USA, China, Australia and Angola are also major distributors of petroleum products, the distribution of petroleum products in Nigeria is often characterised by problems of petroleum products unavailability and irregular supply leading to scarcity of the products. Thus, in spite of the various efforts by Nigeria Government to improve on the distribution of petroleum products, the performance of this sub-sector, do not meet the expectation of Nigeria consumers, policy- makers, industrialists and analysts. For example, there are often outcries of scarcity of petroleum products in the country despite claims by the government to have increased daily supply and distribution. It was reported that the fuel supply and distribution challenges faced by Nigerians prompted NNPC by December of 2012, to exceed the normal national daily consumption level by pumping and supplying an average of over 41 million litres per day to be distributed to fuel stations nationwide in excess of the national daily consumption of 30-33 million litres (NNPC News, 2012). Despite these efforts, Nigerians still experience fuel scarcity and non- availability of products at filling stations leading to black marketing till date.

Nigeria's crude oil production up till date averaged 2.2 million barrels per day (NNPC Report, 2017). The Nigeria National Petroleum Corporation (NNPC) was established in 1977 to concern itself with the processes of exploration, production, refining, distribution and marketing of petroleum products (Oil and Gas Innovation Centre, 2008). The oil industry has been in existence for more than sixty years, since 1956, when the first discovery was made in Oloibiri, which is now in Bayelsa State, Nigeria. From that time, the Nigeria national petroleum industry has been the source of crude oil to many nations of the world. Since it came into being, NNPC has been statutorily given the mandate for the exploration of crude oil and distribution of refined petroleum products nationwide (Braide, 2003). This it does in two ways, the upstream sector and the downstream sector.

The upstream sector involves the search for, discovery and production of oil and gas (Obi, 2009). The downstream sector consists of refining, supplying and distribution activities. Petroleum products are 
distributed via pipelines, road (bridging), and by rail (Wabueze, 2007). The actors in the downstream sector involve both the private and public organizations. The public actor is the government and its agents such as NNPC and its subsidiaries, the Department of Petroleum Resources (DPR), the Petroleum Product Regulatory Agency (PPRA), among others. NNPC, through its subsidiary Pipelines and Product Marketing Corporation (PPMC), controls the distribution of petroleum products in Nigeria. The private actors are made up of the indigenous and foreign actors. The indigenous actors are referred to as the independent marketers. The foreign actors usually referred to as major marketers. These are licensed by NNPC to market and distribute petroleum products in Nigeria. They purchase petroleum products at the twenty-two NNPC storage depots in the country (Mbendi, 2011) and then distribute them to various retail outlets within the country. All of these groups in addition to NNPC, have various distribution strategies or channel networks to facilitate the distribution of petroleum products in Nigeria. Also working alongside these marketers, are other bodies like the Transporters, Export Traders, Independent Inspectors, Vessels Agents, Department of Weights and Measures, Department of Petroleum Resources, and the Petroleum Monitoring Units, whose statutory function is to provide the needed services to aid in the distribution of petroleum products.

It is bizarre to note that Nigeria, with all its credentials as one of the world's highest producers and exporter of crude oil and its products, is incessantly experiencing scarcity of petroleum products epitomized by long queues at filling stations. The refined product shortages and scarcity experienced by Nigerians given the availability of oil resource, the country's ranking in the world and how Nigeria has exported crude oil to other countries (the U.S., Canada etc.), is the paradox that Nigerians experience daily. The irregularity in the availability of petroleum products and scarcity has put Nigeria in agony and tragedy of uncertainty.

Distribution encompasses all the physical activities necessary to make products or services available to customers when and where they are needed. One of the objectives of a sound distribution system is to be both effective and efficient, that is, the system must deliver products or services to the right place, in the right amount, in the right condition, at the right time and also at the right cost (Cuellar, 2011).

The performance assessment of any strategy in a system provides necessary feedback information to reveal progress and diagnose inherent problems within the system. These determine the impact of these strategies on the performance of the organisation. This is in line with Danciu (2010) assertion that once strategies begin to wear out they begin to lose their impact on the performances of the organisation. According to him, the mutual attraction between the marketing strategy and the performance of the company is known as the law of marketing gravity. And that once a marketing strategy loses impact on the marketing performance as a result of the law of marketing gravity a fundamental change is needed.

This paper points out that, the strategies, so far put in place by NNPC for the distribution of petroleum products in Nigeria, are either not implemented properly or have been inconsistent or are inappropriate, or have lost their impact to address the problems of petroleum product distribution in Nigeria. In other words such strategies are now been affected by the law of marketing gravity and need to be changed or revisited. Just as Danciu (2010) puts it that even if marketing strategies are developed only for success, such strategy could at one moment in time lose its attractiveness for the company. According to him such a phenomenon is due to lack of sensitivity and self-sufficiency. In Nigeria historically, studies have shown that the distribution arm of NNPC as a company has typically gone through long periods of relative continuity during which established distribution strategies remained largely unchanged since its inception in 1977.

\subsection{Literature Review}

In the contemporary rapidly changing business world, it is common place to see organisations managing to survive when they are not strategically dynamic. As Danciu (2010) succinctly puts it that often the strategies relied upon by this organisations for success often lose their effect on performance as a result of strategic wear out/drift. In the context of increasingly complex and dynamic environments, such events seem to have a stronger and more abrupt impact on the concerned firms. The example of the distribution arm of the Nigeria National Petroleum Industry (NNPC) corroborate this observation. In Consistent with Danciu (2010) thoughts, this paper focus on how NNPC operates in a more dynamic, fast-paced environments than it did a few decades ago and how it faced environmental pressures representing the driving forces that has push it out of its comfort zone, prompting it to face the risks that change creates which may make it stand the risk of strategically drifting away from its initial purpose.

The concept of strategic drift was introduced by Gerry Johnson in 1988. He defined

It as the misfit between the changes in the organization's strategy and its environment. Starting from 'Logical incrementalism' concept, Johnson argued that managers build their apprehension of external stimuli and their understanding of the environment based on a homogeneous and rather stable view. Thus, they tend to adjust only gradually the company's strategy following unconsciously their preconceived view. This strategic evolution path might eventually deviate from the environment development course, leading the organization to a strategic drift situation.

Though Johnson did not explain neither the consequences that drifted companies might face, nor describe the factors that could lead to a similar situation; besides, he tends to perceive the explanation of a strategic drift as rather internal (the choice of an incremental evolution of the strategy), than external (unexpected 
environment change), but Both oversights were revised few years later by the same author. He redefined strategic drift as the progressive failure of existing strategies to address the competitive position of the company, Johnson grants a more crucial role to environmental changes. Besides, he admits that the inability of organizations to acknowledge and address these "strong forces at work" causes inevitably a performance decrease.

According to him, two main factors explain strategic drift situations: first, an increasingly complex and dynamic external environment and second, leadership myopia to recognize that the adjustments made on the business strategies are not able anymore to follow the environmental changes.

\subsection{Development of Strategic Drift Factors}

Starting from the duality of factors, external and internal to the organisation, Gilligan and Wilson (2009) provides more details about potential strategic drift factors. From the environment side, he gives the examples of changes in market structure and competitive landscape, the evolution of consumers' expectations as well as legislative and technological changes. As internal factors, they mentions poor investment and cost control management, and weary managerial philosophy.

Gilligan and Wilson (2009) also introduced the concept of strategic wear-out. He explains that if the company fails to anticipate early enough the external changes by modifying consequently its course, even the most successful strategies would inevitably wear-out and lead to failure. He suggests the 'gravity law of marketing' concept, where past strategic choices don't guarantee future success, as in spite of how big or powerful an organization or brand becomes, sooner or later its performance will almost inevitably decline.

Dwyer and Edwards (2009) and Danciu (2010) support that the 'gravity law of marketing' is not universal as it applies only to complacent companies who are not mindful of Cumulative change. Danciu (2010) asserts that strategic drift appears where the strategy progressively fails to address the strategic position of the company and how performance deteriorates. This thoughts match the present position that NNPC has found itself. As mentioned before, NNPC from inception has depended on a particular pattern of operation since it came into being. NNPC has been statutorily given the mandate for the exploration of crude oil and distribution of refined petroleum products nationwide (Braide, 2003). This it does in two ways, the upstream sector and the downstream sector.

The upstream sector involves the search for, discovery and production of oil and gas (Obi, 2009). The downstream sector consists of refining, supplying and distribution activities. Despite Nigeria's credentials as one of the world's highest producers and exporters of crude oil and its products, the government involvement, and the involvement of both independent and dependent marketers in the distribution of petroleum products, it is bizarre to note that the country is not free from incessant experience of petroleum product scarcity. The unavailability and inefficient distribution of oil would lead to retardation in the nation's economy leading to stagnation in the wheel of progress. Which means crucial factors in the political life of the nation will be affected and life itself will be horrendous for the populace. That is why the availability of oil and its proper distribution are important issues that the government and the entire nation are concerned with as it also affects the diplomatic strategies of the nation. The irregularity in the availability of petroleum products and scarcity has put Nigeria in agony and tragedy of uncertainty.

The menace of unavailability and shortages of petroleum products has existed in Nigeria for long. In order to reduce these problems, a judicial commission of inquiry was set up as far back between 1974 and 1975 to ascertain the causes of the shortages and suggest remedial measures. The commission observed that, lack of effective distribution channels and facilities for the distribution of products was a fundamental factor. Based on their findings, pipeline systems and storage depots were provided to bring relief (Akpoghomeh \& Badejo, 2006). But, from 1990, the problem of severe petroleum products shortages resurfaced again. All attempts by government agents to curb this problem proved inadequate. This proves to be a lingering strategic issue and it is worrisome. If as far back as in the 1970s, it was observed that effective distribution channels and adequate facilities were important factors in the efficient distribution of petroleum products, but that same problem that led to this discovery still remained unresolved then, this shows a clear case of a strategic drift or wear-out.

NNPC is driven by the urge to reach more Nigerians with the usual distribution practice. The excessive attachment of NNPC's and its leadership to the strategies and the capabilities, at the origin of its inception in the petroleum industry, contributes to its inability to make products available regularly when needed. This results to the inevitable strategic drift experienced in the industry. The drift has defied every attempt by Nigeria government and its agents to distribute petroleum products equitably. An example of such a drift can also be seen from what happened to Nokia Company as noted in the work of Dziri (2011) where Nokia tried to reach more users with the same investment from its platform which weakened considerably its competitive position in smart phones leading to strategic drift. As stated in the work of Gilligan and Wilson (2009) His work provides more details about potential strategic drift factors. From the environment side, he gives the examples of changes in market structure and competitive landscape, the evolution of consumers' expectations as well as legislative and technological changes as internal factors, they mentioned poor investment and cost control management, and weary managerial philosophy. Gilligan et al also introduces the concept of strategic wear-out. He explains that if the company fails to anticipate early enough the external changes -by modifying 
consequently its course-, even the most successful strategies would inevitably wear-out and lead to failure. This agrees with Danciu (2010) view that any marketing strategy developed for success, could at any moment in time lose its attractiveness and impact on company performance. Based on this Gilligan and Wilson (2009) suggests the 'gravity law of marketing' concept, where past strategic choices don't guarantee future success, as in spite of how big or powerful an organization or brand becomes, sooner or later its performance will almost inevitably decline.

Dwyer and Edwards (2009) and Danciu (2010) support that the 'gravity law of marketing' is not universal as it applies only to complacent companies who are reluctant to change their current winning strategies. The three authors consider that facing dramatic environmental changes, companies can react proactively and implement strategic shifts.

Concerning the explanation of strategic drift, Danciu proposes four sets of causes: Change in consumers' expectations and needs, change in market structure and competition, change in macro-environment and internal strategies. NNPC in Nigeria can identify with this causes in its distribution arm of the industry. From the inception of NNPC in 1977, the population of Nigeria has increased tremendously, there is increased usage of petroleum products, both for business and personal usage, increase in the influx of automobile, increase in diversion of the products, theft and the vandalisation of products (wilful damage or sabotage of the pipeline by some unpatriotic Nigerians with the intention to steal petroleum products for economic reasons or for express political grievances) is on the increase, communities agitations and effect of the political environment is on the increase yet the strategy of petroleum products distribution seems to remain the same.

Decrees were created by successive military regimes in Nigeria with stiff penalties (Death by firing squad or 21 years imprisonment) but to no avail. Vandals, bunkers, those who hoard products and many others involved in unwholesome practices collaborate and feast on the Nigeria's oil and when arrested, they are released afterwards. For Nigeria to achieve effective product distribution, its strategy must change and its laws must work not only on the poor but also on the rich in the country. For instance, in Australia, the quality of service monitoring for product distribution service typically, relates to the reliability of product supply, i.e. the provision of continuous product supply to customers, network integrity, gas leaks, the effectiveness of operational and maintenance activities, customer service responsiveness to issues such as complaints and reported gas leaks. Distributors of products in Australia must meet guaranteed service levels or pay penalties for breaches (State of the Energy Market, 2009).

\subsection{Conclusion}

In collusion for the distribution arm of NNPC to attain its ultimate objective of identifying and satisfying Nigeria's needs and wants within the downstream sector, It is important for NNPC to assess it's performance against the standard of accuracy, completeness, cost and speed set, and this also depends on its ability to simultaneously explore new opportunities and exploit existing ones to avoid strategic drifts. It is advisable for NNPC to capture early signals of turbulent environment and prepare itself with a resilient culture and organizational structure. In case of already drifting situation as NNPC's (Danciu, 2010) calls for a strategic shift and considers that surviving a strategic drift is a matter of change management that requires 3 elements: awareness, will and capability. In addition, the Government of Nigeria most be willing to enforce the rule of law in Nigeria irrespective of who is involved, not by words but by actions, without which no tangible result will be achieved.

Also NNPC must be open to change and avoid stagnation that contributes to the marketing gravity law and should act on a solid ground of strategic management of change. NNPC could chose between adaptation and evolution or reconstruction and revolution as change of the marketing strategy depending on the degree of the strategic drift or wear out.

\section{References}

Akpoghomeh, O. S., \& Badejo, D. (2006). Petroleum product scarcity. A review of the supply and distribution of petroleum products in Nigeria. OPEC review. [Accessed, 30/11/2017].

Braide, K. M. (2003). The mechanic and dynamic of fuel scarcity in Nigeria. Retrieved from http://nigerdeltacongress.com/articles/mechanics_dynamic_of_fuel.[Accessed 19/6/2016.

Cuellar, S. (2011). Marketing module distribution. [Accessed, 4/4/2017].

Danciu, V. (2010). The gravity law of marketing - a major reason for change to a better performance. Theoretical and Applied Economics, 4(545), 7-18.

Dwyer, L., \& Edwards, D. (2009). Tourism product and service innovation to avoid 'strategic drift'. International Journal of Tourism Research, 11(4), 321-335. Available at: https://doi.org/10.1002/jtr.690.

Dziri, R. (2011). Avoiding strategic drifts in a hypercompetitive market analysis of Nokia's position in the mobile phone industry and suggestions. Unpublished MBA Thesis in Berlin School of Economics and law, European-Asian Management.

Gilligan, C., \& Wilson, M. S. R. (2009). Strategic marketing management: Planning, implementation and control (3rd ed.). Oxford (UK): Elsevier Butterworth-Heinemann. .

House of Representative Report. (2012). To verify and determine the actual subsidy requirements and monitor the implementation of the subsidy regime in Nigeria. Resolution No. (HR. 1. 2012) Nigeria: Abuja.

Mbendi, I. (2011). Petroleum products wholesalers in Nigeria. Overview. [Accessed, 14/6/2016].

NNPC. (2006). Annual statistical bulletins. [Accessed, 2/7/2016]. 
NNPC News. (2012). Petroleum product distribution by zones. NNPC Annual Statistical Bulletin. [Accessed, 4/1/2017]. NNPC Report. (2017). Upstream ventures. [Accessed, 4/6/2008].

Obi, C. I. (2009). Oil extraction, dispossession, resistance and conflict in Nigeria's oil - rich Niger Delta. Uppsala: Nordic African Institute.

Oil and Gas Innovation Centre. (2008). A commentary on petroleum industry bill. Abuja, Nigeria: The Oil and Gas Sector Reform Implementation Committee.

State of the Energy Market. (2009). Gas distribution business comparative performance report. Melbourne. Retrieved from www.aer.gov.au. [Accessed, 2/5/2015].

Wabueze, T. (2007). Product loss and PHRC tank farm operations. Unpublished NNPC (Nigeria National Petroleum Corporation (NNPC) Chief Officers' Thesis, Nigeria. 